\title{
Informe Desarrollo Humano en Chile 2015: Los tiempos de la politización. Programa de las Naciones Unidas para el Desarrollo (PNUD) Chile. Santiago de Chile. 2015. pp. $268^{1}$.
}

\author{
Juan Pablo Paredes P.*
}

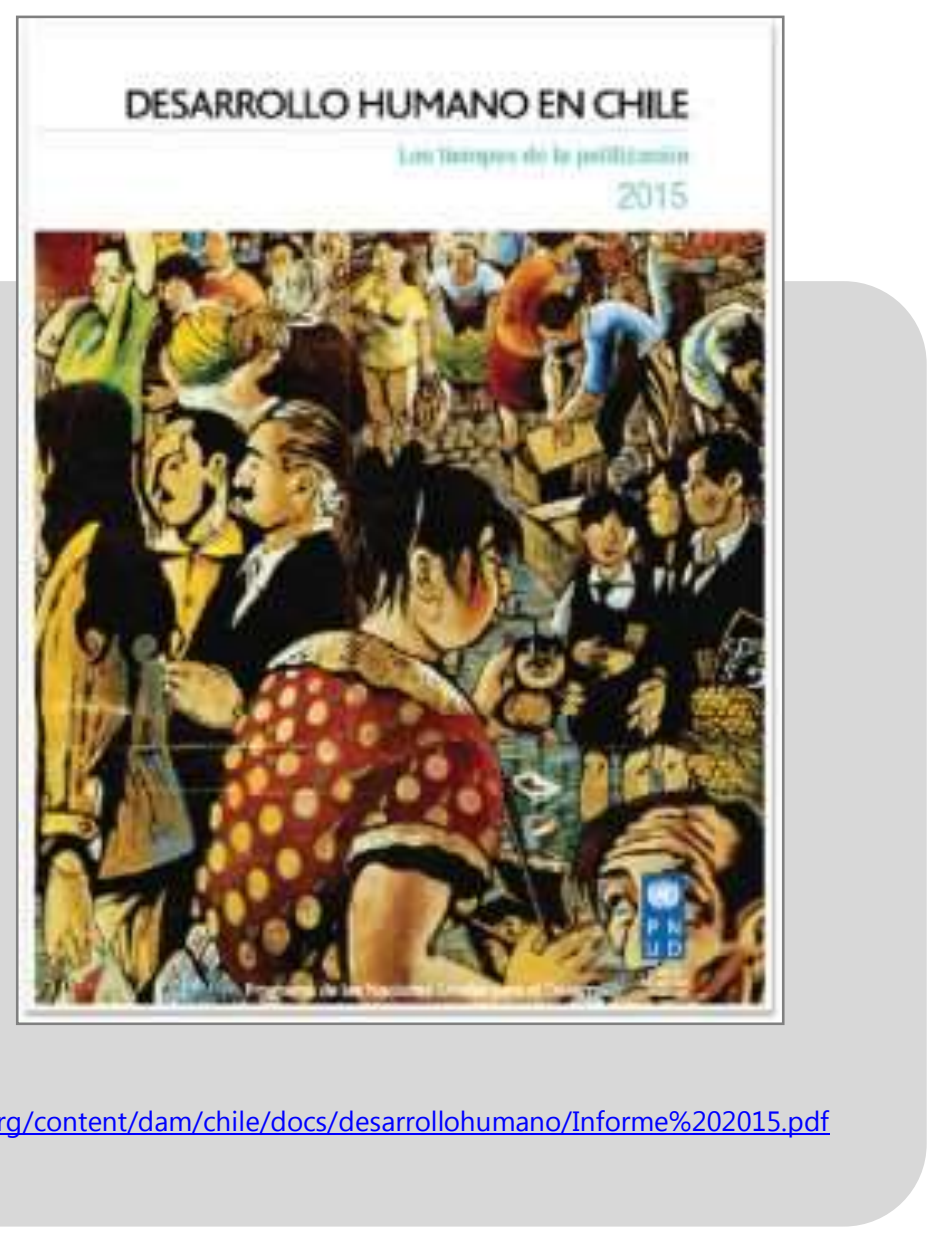

\footnotetext{
${ }^{1}$ Reseña elaborada en el marco del Proyecto Fondecyt Regular N 1150788 "Nuevos estudios de la ciudadanía en Chile: Historia, Transformaciones y Espacios", financiado por Conicyt- Chile.

* Investigador asociado. Instituto de Asuntos Públicos, Universidad de Chile.
} 
El cántico ciudadano y popular "Chile: la alegría ya viene eeehh/ Chile: la alegría ya viene eeehh" se escuchaba en todas las calles del país con el triunfo del NO en el plebiscito del año 1988. Con tal triunfo, luego de un periodo álgido de movilizaciones populares antidictadura y con un posterior proceso eleccionario prodemocracia, se daba por finalizada la dictadura de Augusto Pinochet y, junto a ello, nacía la esperanza democrática. El periodo transicional de los años 90 estuvo marcado por el dictum 'la medida de lo posible', es decir, justicia, igualdad, reconocimiento, derechos, en resumen, la democracia solo en la medida de lo posible con tal de no abrir las heridas del pasado, ni invitar al conflicto social. La figura del orden tomaba el escenario democrático. La década de 2000 estuvo marcada con la consolidación del orden democrático. Las semánticas del consenso, de la gobernabilidad y de la seguridad reemplazaron a las expectativas de la alegría. 'Las instituciones funcionan' fue el corolario de 'la medida de lo posible'. Con ello se consolida la democracia de los acuerdos, de la élite político-económica y se instituye una gramática pública elitista y anticiudadana. Tal gramática presenta una raigambre nerudiana, diciéndole a la ciudadanía: "Nos gusta cuando callan porque están como ausentes". Con la consolidación de la democracia de los acuerdos, la esperanza se transformó, para la ciudadanía, en espera. Los ciudadanos fueron subjetivizados como pacientes. La democracia pasó a ser una aburrida promesa de tiempos mejores expresada como un largo letargo político ciudadano.

Con todo, algo ha ocurrido en Chile en el último lustro. A partir del segundo semestre de 2010, después del terremoto y en pleno ejercicio del primer gobierno de derecha postdictadura, algo se agita en el país. En una multiplicidad de ocasiones hemos sido testigos de ver en las calles a más de cien mil personas marchando por la defensa de la educación pública, situación que continúa hasta la actualidad; más de cincuenta mil personas marchando contra HidroAysén; un número semejante marchando por la diversidad sexual en cada una de sus manifestaciones. Es de destacar que esas marchas son ciudadanas y que gran parte de los/as participantes son jóvenes. Cifras que corresponden a Santiago y que se disparan en todo el territorio. No solo son marchas, son también carnavales: música y performances multitudinarias, clases y reflexiones en las calles, diálogos y debates públicos, invención y creatividad ciudadanas, videos e intercambios en internet, que inundan incluso nuestros espacios privados. En otras palabras, hemos sido testigos de un espacio público vivo, repleto de gente y con mucho color, que contrasta con el cotidiano invierno que hemos vivido en Chile durante tantos años. También hemos sido testigos de las demandas locales y territoriales específicas: Magallanes, Aysén, Freirina. Por su parte, las manifestaciones ambientales también han dado que hablar: punta de choros y el conflicto del agua en 
los valles centrales. Con todo, la voz ciudadana se alza públicamente y el debate público ha rejuvenecido.

Entonces, ¿cómo entender lo que está ocurriendo? ¿Cuáles son sus alcances? EI informe del PNUD en Chile del año 2015, titulado Los tiempos de la politización esboza un diagnóstico y propone algunas claves interpretativas. El punto de arranque del estudio es una constatación: Chile vivencia un proceso de politización (p. 30). Tal proceso de politización significa una nueva situación social para el país en la cual la sociedad chilena discute y reflexiona sobre sí misma: sus características, sus acuerdos básicos, su autonomía y soberanía, y sobre su devenir. En el fondo, la sociedad, vía la politización, vuelve a preguntarse por el límite de lo posible (p. 29).

Tal cuestionamiento de sus propios límites se expresa en la creciente discusión pública que pone en tela de juicio lo naturalizado; se proponen temas y otros actores participan de la discusión, mientras otros temas y actores salen de la palestra pública. El Informe observa que hoy es tan relevante cuestionar la forma como el fondo, es decir, actualmente la sociedad chilena se pregunta el qué y el cómo. Hacerse cargo de sí misma (la sociedad), del qué y el cómo de su devenir, es lo que el Informe llamará politización. Lo que estaría en juego en el Chile de hoy, producto de la puesta en cuestión de la naturalidad del orden social es la propia constitución de la sociedad, expresado en un cuestionamiento de lo real, lo legítimo y lo posible (p. 18).

El Informe del Desarrollo Humano en Chile, versión 2015, desplegará varias herramientas para demostrar tal proceso de politización, en base a una discusión conceptual consistente y a un trabajo empírico sustancioso -como señalaremos más adelante en los méritos del estudio. Pero su propósito no es solo el de diagnosticar la politización, sino también contribuir a la construcción de una relación virtuosa entre politización y desarrollo humano. Para hacerlo el estudio divide su escrito en 9 partes.

La Parte 1 se presenta e introduce el Informe en su problematización y alcance. En la Parte 2 se discuten los conceptos que configuran el ojo analítico del Informe, vía la presentación del concepto de politización a partir de una distinción básica entre la política y lo político. La Parte 3 analiza las pugnas de politización en el espacio público. En la Parte 4 se describe la imagen que tiene la ciudadanía acerca del momento actual del país, es decir, el diagnóstico ciudadano. En la Parte 5 se deja ver la noción de lo político que existe en las representaciones de los ciudadanos y las tensiones que impactan en la politización a partir de las creencias básicas de los chilenos y chilenas acerca del orden, la democracia, la representación y la toma de decisiones. En la Parte 6 se observan las formas en que estos procesos confluyen y derivan en diversos modos de involucramiento con lo político. La Parte 7 analiza el papel de los movimientos sociales en los procesos de politización y su relación con la subjetividad de la ciudadanía. En la Parte 8 se pasa revista a la mirada de las élites del poder en Chile. Estas imágenes se contrastan en el Informe con las opiniones de la ciudadanía. En la 
Parte 9 se sintetizan los principales hallazgos, se pregunta por las consecuencias de la politización y por el desafío que este proceso representa para la sociedad chilena, con miras a hacer de este un aporte para la construcción del desarrollo humano. Para ello, el Informe se propone como un mapa de las tensiones subyacentes al proceso, de sus riesgos y oportunidades, con el objetivo de ofrecer pistas para la deliberación social futura.

Descrita la estructura del Informe, vamos a sus méritos, partiendo de la definición conceptual de su diagnóstico: la politización.

Politizar consiste en transformar -o al menos intentarlo- en político un asunto que antes no lo era. Esto es, hacerlo partícipe de un proceso de debate y toma de decisiones colectivas. Mediante la politización, la sociedad reflexionará sobre sí misma y sus límites. Conceptualmente, la idea de politización se sustenta en la distinción entre lo político y la política. El Informe en este punto seguirá la discusión de autores/as como Chantal Mouffe, Ernesto Laclau, Jacques Ranciére y Cornelius Castoriadis, asumiendo una posición marcadamente posfundacionalista. Para el Informe, lo político refiere a todo aquello que en una sociedad se establece como susceptible de ser decidido colectivamente. La política, por su parte, es la expresión institucional de un determinado estatus de la definición de lo político. Lo político trasciende a la política, al tiempo que la contiene; para ello, el Informe propone la idea de "politizar la política" ( $p$. 29). Diversos actores participarán de este proceso de politización, sobre todo la inclusión de la ciudadanía en la definición de problemas dignos de ser tratados políticamente. Estos actores desarrollarán diversas pugnas de politización -disputas por la expansión o contracción de lo posible. La politización asegura tal proceso de disputa pública, mas es contingente y con ello no puede asegurar el resultado. Politización es el desborde del consenso, su desnaturalización. Este es el primer mérito del informe: el diagnóstico realizado.

La politización en tanto proceso, entonces, opera. Actúa y se despliega, no siendo posible evadirla, tampoco es posible definirla antes de que emerja. Es, por ende, un proceso heterogéneo que no puede reducirse a una lectura simplificadora o lineal. He aquí uno de los méritos del Informe: su valor de estudio empírico. El Informe propone e implementa una forma rigurosa y consistente de indagar y seguir un proceso sociopolítico, actualmente abierto, con las herramientas que aportan las ciencias sociales para tanto. El Informe, metodológicamente hablando, propone un dispositivo relacional de indagación empírica mixta, en tanto utiliza datos cuantitativos y cualitativos, que le permiten relacionar varias categorías y niveles analíticos. ${ }^{2}$ El Informe permite 'ver' la politización y eso es un gran mérito.

\footnotetext{
${ }^{2}$ Para detalles metodológicos ver los anexos del Informe. Pp. 223-255.
} 
El dispositivo analítico desplegado por el Informe permite observar e interpretar el proceso de politización en lo que atañe a las implicancias individuales y subjetivas del proceso. También propone una observación de los alcances macro del proceso de politización en relación con el plano institucional. Pero el Informe también propone un nivel intermedio entre ambos polos, algo así como un nivel meso de análisis, que les permite relacionar discursos y acciones de los niveles individuales-subjetivos con el nivel institucional. Este nivel meso corresponde a lo que en el Informe se denomina la dimensión colectiva y pública del debate gatillado por el proceso de politización. Desde una propuesta relacional, el Informe vincula en sus análisis las descripciones de cada una de estas dimensiones, pero también sus interrelaciones. El proceso de politización de la sociedad chilena dice tener relación con todo el conjunto de la vida social y no solo con esferas limitadas de ella. Implica lo subjetivo-individual (micro), lo colectivo y público (meso), y lo institucional (macro). Este juego categorial y de vinculación de niveles analíticos en tanto capacidad interpretativa es otro de los méritos del texto aquí comentado.

El Informe también presenta valor por sus 'hallazgos' en lo referido a la politización. Vista como proceso, la politización es una manifestación heterogénea y plural. La politización ocurre en varios ámbitos y esferas. Se multiplican las arenas de debate público: educación, salud, trabajo, seguridad, medio ambiente. Surgen nuevos actores, otras voces aparecen en escena. Es decir, el escenario se complejiza, pero insisto, el Informe deja ver el proceso de politización del Chile reciente.

Sin embargo, de acuerdo a mi lectura del informe, la politización es un proceso que no tiene su trayectoria asegurada. Es un proceso contingente y sin garantías de éxito, y con esto deja ver su fragilidad. Es un proceso de experimentación ciudadana y pública que permite posiciones dispares: momentos de creatividad y oportunidad, momentos de amenaza e incerteza sobre el futuro y la seguridad adquirida en el presente. En la actualidad, nos dice el Informe, la politización nos obliga, como sociedad, a plantearnos preguntas que no estamos en condiciones de responder. He aquí la principal fuerza de la politización, su condición de negatividad que desnaturaliza el orden social. Pero, he ahí también su principal peligro, la incertidumbre del futuro.

En resumen, en los últimos cuatro años un fantasma recorre las calles de Chile: el fantasma de la politización. Pero tal fantasma no solo recorre las calles, la ciudanía se agolpa en sus plazas para debatir públicamente, se toman los colegios y las universidades para practicar y producir formas democráticas, se resignifica el espacio público y se interpela a la sociedad toda, en fin, es un fantasma que invita a experimentar la forma de vida democrática. El Informe del Desarrollo Humano en Chile, versión 2015, deja en evidencia la existencia de tal fantasma. Frente a esto, la élite social, política y económica, junto a sus instituciones, reacciona con desconcierto, mientras la opinión pública y las organizaciones ciudadanas lo expresan en sus debates. 
Los 'tiempos de la politización' colocan nuevamente en el tapete público la pregunta ¿qué hacer? El problema que deja ver el Informe es que nadie sabe cómo responder a ello, pero la politización de la sociedad también pone el problema del tiempo en relación con la premura de las decisiones. Algo se debe hacer frente a las demandas de cambio. Y, si bien la sociedad no propone la solución -obviamente no puede hacerlo-, insinúa la forma de un mecanismo: sin la ciudadanía no es posible realizar cambio alguno a la situación actual. De tal forma, se vislumbra a partir del Informe que el foco del problema se suscita en el modo de concretarlo, en el cómo hacerlo. Al leer el informe suena en el fondo el viejo Luca Prodan y esa pulsión permanente, "no sé lo que quiero, pero lo quiero ya". La ciudadanía en Chile, según el Informe, presenta el mismo dilema, pero cuenta con una certeza: sabe que ella es fundamental para implementar cualquier cambio. 